\title{
Biventricular assist device implantation as bridge to transplantation after Mustard procedure
}

\author{
Abdul Rahman Dakkak, MD, Angelo M. Dell'Aquila, MD, Juergen R. Sindermann, PhD, and \\ Andreas Rukosujew, PhD, Muenster, Germany
}

We present a case of a 30-year-old man who underwent an atrial switch operation (Mustard procedure) at age 5 months due to a transposition of the great arteries.

At age 29 years, several hospitalizations were required due to recurrent cardiac decompensation with dyspnea and leg swelling. Cardiac magnetic resonance imaging showed a highly reduced systolic function of the hypertrophied systemic ventricle (ejection fraction, 16\%) and the significantly dilated pulmonary ventricle (ejection fraction, $10 \%$ ). The patient's clinical condition deteriorated rapidly with beginning multiorgan failure. Medical management was only partially successful; therefore, we opted for biventricular support. A HeartWare ventricular assist device (VAD) pump (HeartWare Inc, Framingham, Mass) was chosen for its small size and for the consequent possibility of intrapericardial implantation.

\section{CLINICAL SUMMARY}

Median resternotomy and dissection of cardiac adhesions were performed after starting the extracorporeal circulation. Connection to the heart-lung machine was achieved via cannulation of the left common femoral artery and the femoral vein. The HeartWare pump housing was connected to the apex of the anatomical left ventricle (pulmonary ventricle), whereas the outflow cannula was connected to the pulmonary artery. This was narrowed just before the anastomosis with the pulmonary artery using a Hegar dilator to a diameter of $7 \mathrm{~mm}$. A second HeartWare pump was placed in the area of the inferior wall of the anatomical right ventricle (systemic ventricle) (Figure 1). Before VAD placement all visible trabeculations that could have potentially compromised blood flow were resected. Moreover, because of ventricular dilation no polytetrafluoroethylene felt ring between sewing ring and inflow cannula was necessary. This, as described in our previous report, ${ }^{1}$ allowed a

From the Division of Cardiac Surgery, Department of Cardiothoracic Surgery, University Hospital Muenster, Muenster, Germany.

Disclosures: Authors have nothing to disclose with regard to commercial support. Received for publication July 8, 2014; revisions received Aug 11, 2014; accepted for publication Aug 18, 2014; available ahead of print Oct 1, 2014.

Address for reprints: Abdul Rahman Dakkak, MD, Albert-Schweitzer Campus 1, 48149 Muenster, Germany (E-mail: abdul.dakkak@ukmuenster.de).

J Thorac Cardiovasc Surg 2014;148:e243-4

$0022-5223 / \$ 36.00$

Copyright (c) 2014 by The American Association for Thoracic Surgery

http://dx.doi.org/10.1016/j.jtcvs.2014.08.046

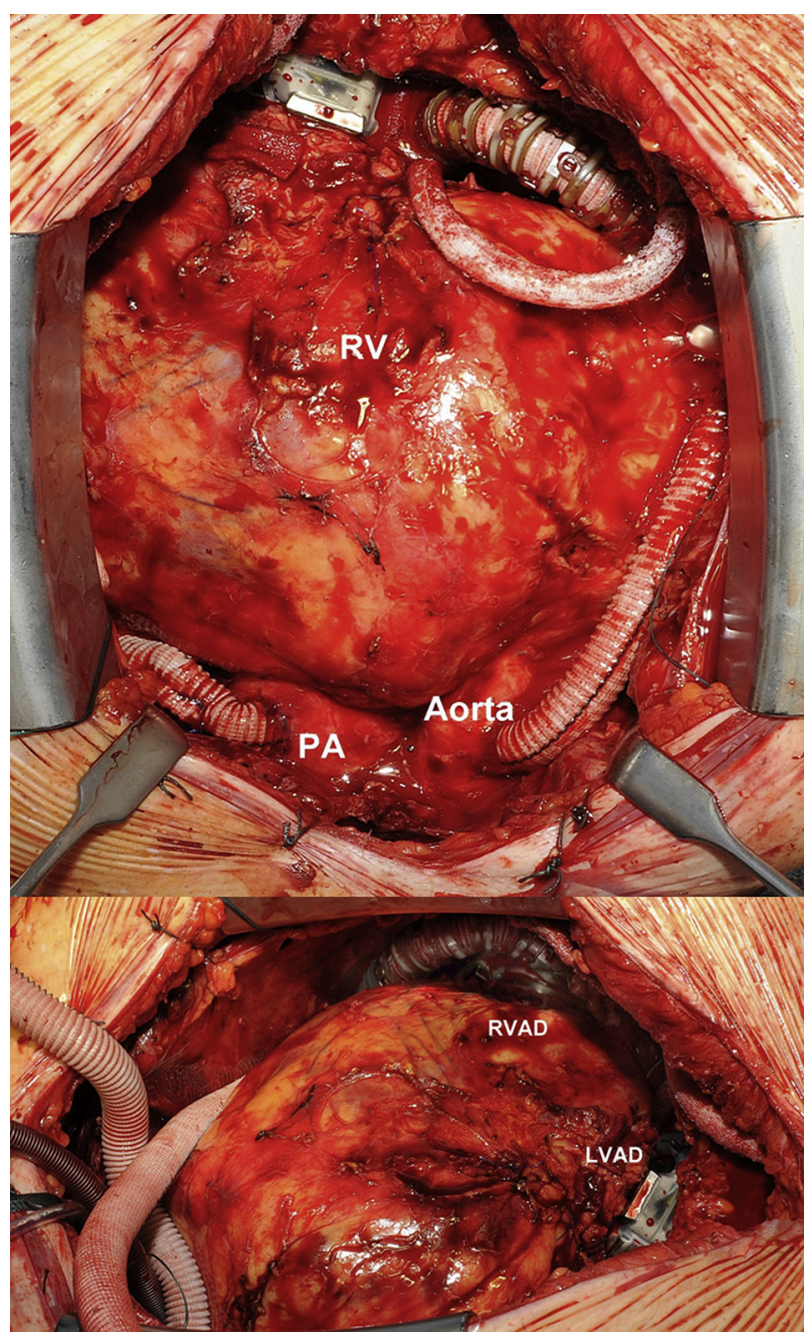

FIGURE 1. Upper panel, The left ventricular assist device (systemic ventricle) and the anatomical structures. Lower panel, The left ventricular assist device (systemic ventricle) and the right ventricular assist device (subpulmonary ventricle). $L V A D$, Left ventricular assist device; RVAD, right ventricular assist device; $R V$, right ventricle; $P A$, pulmonary artery.

shorter length of the inflow cannula in the regular right VAD implantation.

During the patient's intensive care unit stay his hemodynamic functions were stable, with a mean blood pressure of $\sim 60$ to $70 \mathrm{~mm} \mathrm{Hg}$, achieved through right VAD and left VAD flows of 3.0 and 3.5 to $3.7 \mathrm{~L} / \mathrm{min}$, respectively (Figure 2). On the 10th postoperative day a 


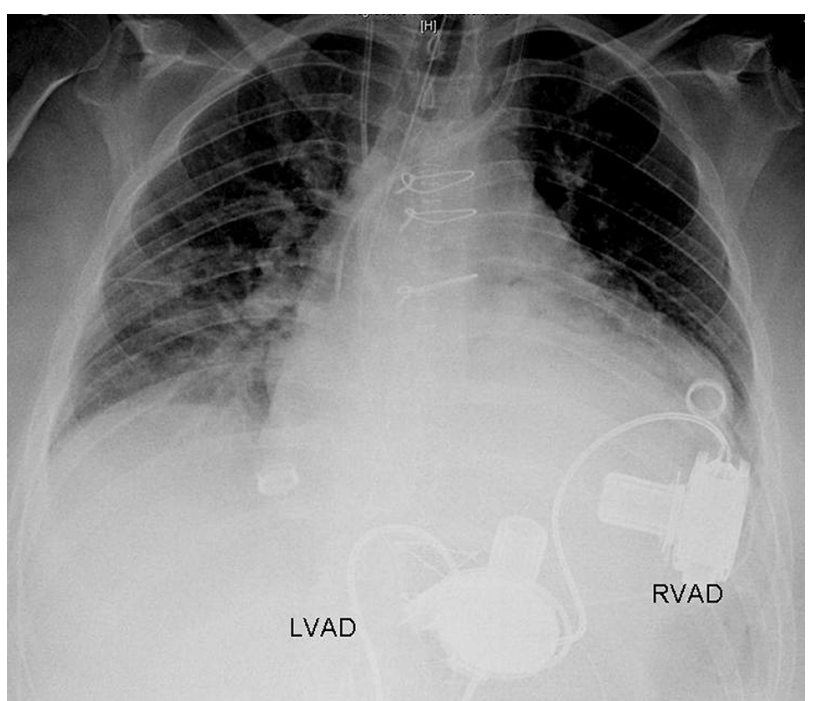

FIGURE 2. Chest radiograph showing both ventricular assist devices and their position. $L V A D$, Left ventricular assist device; $R V A D$, right ventricular assist device.

transient tracheotomy was performed because of prolonged respiratory weaning. A postoperative initial elevation in bilirubin values decreased spontaneously during the first 2 weeks. The patient was increasingly mobile and on the 25th postoperative day the tracheal tube was removed. Warfarin and aspirin were administrated for anticoagulation (international normalized ratio target, 2.5-3) and antiplatelet therapy, respectively. After 6 months of follow-up the patient is in good condition on an outpatient basis.

\section{DISCUSSION}

VAD implantation with a single pump for supporting the right (systemic) ventricle may not be sufficient in the presence of biventricular failure. In this regard, biventricular support has to be preferred. Considering the anatomic characteristics of patients after Mustard procedure, biventricular VAD implantation constitutes a special surgical challenge. The moderator band and the trabeculation of the morphologic right ventricle represent a demanding surgical issue for the insertion of the left VAD pump (systemic ventricle). The apex of the right (systemic) ventricle contains many trabeculae that could limit the inflow leading to low drainage. In addition, the size of the used VAD plays an important role in the surgical procedure.
Special attention is required in placing the inflow pump in the right ventricle to guarantee an unobstructed flow in and out of the device. Wiklund and colleagues ${ }^{2}$ reported a case of HeartMate I (Thoratec Corp, Pleasanton, Calif) left VAD (systemic ventricle) implantation in a patient aged 15 years after Mustard operation. Due to the anatomic and topographic factors, the HeartMate I left VAD (systemic ventricle) had to be implanted back to front, with the inflow directed toward the diaphragmatic wall of the right ventricle and the outflow toward the apex region. In our case, this was not necessary because of the smaller HeartWare pump dimensions.

Another concern is pulmonary outflow. To increase the pump afterload and to avoid excessive lung perfusion with possible consequent pulmonary edema, the outflow graft of the right VAD was narrowed ${ }^{1}$ to a diameter of $7 \mathrm{~mm}$.

There are many studies on the use of biventricular assist devices in patients with acquired cardiomyopathy of different etiopathogenesis. ${ }^{3,4}$ There are also several reports on systemic VADs in patients after Mustard procedure. ${ }^{5}$ However to our best knowledge, a comparable case has not yet been described in the literature.

As a result, the use of biventricular cardiac support systems is no longer a rarity. Treatment of adult patients with congenital heart failure who underwent surgical correction in childhood is a major challenge for cardiologists and surgeons. With an increasing number of patients requiring heart transplantation and the presence of donor shortages, biventricular mechanical support could represent a valid alternative in patients with complex congenital heart disease.

\section{References}

1. Dell' Aquila AM, Schneider SR, Schlarb D, Redwan B, Sindermann JR, Ellger B, et al. Initial clinical experience with the HeartWare left ventricular assist system: a single-center report. Ann Thorac Surg. 2013;95:170-8.

2. Wiklund L, Svensson S, Berggren H. Implantation of a left ventricular assist device, Back-To-Front, in an adolescent with a failing Mustard procedure. J Thorac Cardiovasc Surg. 1999;118:755-6.

3. Hetzer R, Krabatsch T, Stepanenko A, Hennig E, Potapov EV. Long-term biventricular support with the HeartWare implantable continuous flow pump. J Heart Lung Transplant. 2010;29:822-4.

4. Krabatsch T, Potapov E, Stepanenko A, Schweiger M, Kukucka M, Huebler M, et al. Biventricular circulatory support with two miniaturized implantable assist devices. Circulation. 2011;124(11 Suppl):S179-86.

5. George RS, Birks EJ, Radley-Smith RC, Khaghani A, Yacoub M. Bridge to transplantation with a left ventricular assist device for systemic ventricular failure after mustard procedure. Ann Thorac Surg. 2007;83:306-8. 